\title{
POTENSI KITAR SEMULA BAHAN BUANGAN PLASTIK BAGI PENGHASILAN PRODUK KREATIF
}

\author{
MD KHAIRIL HAFIZI MUHAMAD* \\ AHMAD RASDAN ISMAIL**
}

AB AZIZ SHUIB***

\begin{abstract}
Abstrak
Kajian ini telah dijalankan untuk menentukan potensi plastik banner yang dibuang dari industri pengiklanan di Kemaman, Terengganu. Tiga jenis industri pengiklanan yang terlibat dalam kajian ini termasuklah industri iklan yang diwakili oleh Orchid Design and Printing Sdn. Bhd; Industri kitar semula plastik yang diwakili oleh RD Paper Sdn. Bhd dan badan berkanun, Majlis Perbandaharaan Kemaman (MPK). Pelupusan dan pembakaran terbuka terhadap bahan buangan plastik banner yang diamalkan oleh kebanyakan industri pengiklanan menyumbang kepada pembaziran dan pencemaran alam sekitar. Dalam usaha untuk mengawal ini, kajian terperinci mengenai potensi menggunakan plastik banner sebagai alternatif untuk menghasilkan produk kreatif telah dilakukan. Kajian terhadap plastik banner menumpukan kepada dua isu. Pertama adalah kajian mengenai jenis plastik banner. Ini melibatkan dua proses: satu, mengasingkan warna dan jenis plastik banner; dan kedua, mengukur panjang, lebar dan berat plastik banner. Kajian kedua memberi tumpuan kepada proses penghasilan produk melalui pembakaran. Penemuan daripada kajian ini menunjukkan bahawa kaedah menggunakan bahan buangan plastik banner sebagai alternatif untuk menghasilkan produk kreatif adalah satu pendekatan yang berdaya maju bagi memberi nilai kepada hasil sisa buangan serta mencegah pencemaran alam sekitar. Oleh itu, penghasilan produk kreatif hasil daripada kajian ini boleh memberikan pendapatan dan juga mempelbagaikan produk plastik banner yang sedia ada di pasaran komersial.
\end{abstract}

Kata kunci : Plastik banner, Jenis-jenis plastik dan Alam sekitar 


\begin{abstract}
The study was conducted to determine the potential of discarded plastic banner of the advertising industry in Kemman, Terengganu. Three types of advertising industry involved in this study. This includes advertising industry, represented by Orchid Design and Printing Sdn. Bhd; plastic recycling industry represented by RD Paper Sdn. Bhd and statutory bodies of the Treasury Council Kemaman (MPK). Disposal and public burning of plastic waste practiced by most banner advertising industry contributes to wastage and environmental pollution. In the effort to control this, a detailed study on the potential use of plastic banner as an alternative in producing creative products have been conducted. The study of plastic banner focuses on two issues. First is the study of the types of plastic banner. This involves two processes: one is to separate the color and type of plastic banner; and second is to measure the length, width and weight of plastic banner. The second study focuses on the process of production through combustion. This study finds that the using of the waste from plastic banner as an alternative to produce creative products is a viable approach for adding values to the waste and preventing environmental pollution. Therefore, the production of creative products resulting from this research can provide income and also diversify the plastic banner products existing in the commercial markets.
\end{abstract}

Keywords: Plastic banner, Types of plastic and Environment

* Postgraduate Student at Faculty of Creative Technology and Heritage, Universiti Malaysia Kelantan, Malaysia

** Assoc. Prof. at Faculty of Creative Technology and Heritage, Universiti Malaysia Kelantan, Malaysia

${ }^{* * *}$ Assoc. Prof. at Faculty of Creative Technology and Heritage, Universiti Malaysia Kelantan, Malaysia 


\subsection{Pengenalan}

Plastik atau PVC merupakan bahan yang terhasil daripada petroleum, terbentuk daripada rangkaian molekul yang panjang yang samada berselirat ataupun yang melekat dengan kuat. Bahan ini mula diperkenalkan dalam awal abad ke-20 iaitu sekitar tahun 1907-1909 dan penggunaannya terus berkembang dengan cepat. Plastik mempunyai sifat-sifat yang dikatakan menakjubkan dan kewujudannya dianggap sebagai satu bentuk tranformasi alam. Kemampuan bahan tersebut menyamai ataupun boleh mengatasi sesetengah sifat bahan semulajadi yang lain seperti kaca, kayu dan seramik membolehkan penguasaan produk daripada bahan ini berkembang dengan begitu meluas di pasaran.

Plastik adalah bahan organik manusia yang terdiri campuran karbon dan molekul hydrogen. Molekul plastic adalah polimer yang mengandungi susunan rapat dimana organisma seperti bakteria dan fungus tidak dapt memisah secara bio. Plastik boleh terbiodegradasi jika terdedahkan dengan cahaya matahari dan udara untuk jangka masa yang tertentu melalui proses yang dipanggil photo axidation. Bahan plastik digunakan secara meluas memandangkan bahannya yang bersifat kukuh, boleh dipelbagaikan kegunaan serta ringan.

Kebanyakan barangan plastik yang digunakan seharian adalah daripada bahan plastik resin (thermoplastic). Ini adalah kerana plastik daripada jenis ini akan menjadi lembut apabila dipanaskan dan ianya akan memudahkan proses pembuatan. Di antara kumpulan bahan plastik adalah:

1. PET atau PETE (pholythylene terepthalate) selalu digunakan untuk menghasilkan botol minuman.

2. HDPE (High Density Phpolythylene) digunakan untuk menghasilkan bekas susu dan jus serta botol syampu dan botol minyak serta bekas cecair pencuci.

3. LDPE (Low Density Phpolythylene) diguanakan secara meluas untuk beg plastik.

4. PVC (Pholivinyl Cloride) menghasilkan tarpaulin paper, botol minyak masak, bekas cecair pencuci lantai dan bekas bahan cecair.

5. PP (Polypropholyne) bekas majerin, bekas yogut dan kerusi.

\subsection{Komposisi sisa pepejal di Malaysia}

Kadar komposisi sisa pepejal adalah berbeza di antara setiap kawasan kerana ia dipengaruhi oleh beberapa faktor, di antaranya adalah sosio ekonomi dan gaya hidup seseorang. Secara puratanya komposisi sisa pepejal isi rumah di Malaysia adalah seperti Rajah 1.

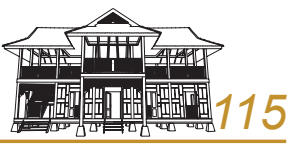




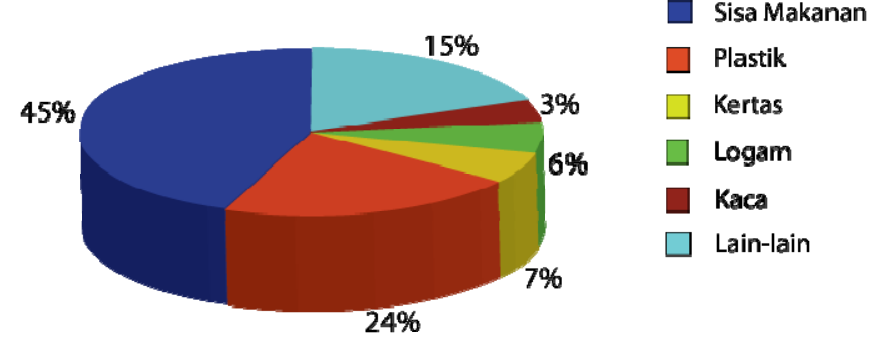

Rajah 1: Purata komposisi sisa pepejal isi rumah

\subsection{Plastik dan kitar semula}

Bermula pada 1980-an, perspektif kitaran hayat sisa plastik menjadi satu pendekatan baru digunakan dalam pengurusan sisa (Christensen 2010). Dalam dekad yang lalu, penilaian kitaran hayat telah digunakan secara meluas dalam pemeriksaan beban kepada alam sekitar, kaedah pelupusan telah dibuat pelbagai untuk sisa yang berbeza. Terutama dalam isu sisa plastik, banyak kajian memberi tumpuan kepada perbandingan kaedah yang berbeza untuk pelupusan sisa plastik. Singer (1994), menyatakan dalam artikelnya bahawa (1) kitar semula pasca penggunaan sisa plastik ketara boleh menyumbang kepada penjimatan tenaga (2) termoplastik adalah lebih untuk dikitar semula berbanding dengan plastik jenis termoset lain yang molekul berstruktur. la adalah kerana termoplastik (termasuk polietilena, polietilena terephthalate, polipropilena, polistirena dan polyvinyl chloride) mengurai apabila dipanaskan; (3) Bahan kitar semula akan menjadi beberapa jenis pilihan yang optimum tetapi perlu digabungkan dengan faktorfaktor ekonomi sosial. Hunt (1995) kitaran hayat untuk kertas dan plastik pelupusan sisa berdasarkan perbezaan alternatif-pembakaran, tapak pelupusan atau kompos. Hasilnya menunjukkan bahawa bersamaan pelepasan $\mathrm{CO} 2$ penting dan boleh terhasil melalui pembakaran plastik, manakala buangan plastik melalui proses penimbusan boleh mengurangkan pemanasan global.

Selain itu, perbandingan di antara kitar semula plastik khususnya untuk membezakan kitar semula kimia dan kitar semula mekanikal (Patel et al. 1999). Perbandingan kaedah pelupusan sisa plastik di Jerman (termasuk tapak pelupusan, pembakaran , kitar semula dan kitar semula mekanikal kimia) dari segi alam sekitar. Hasilnya menunjukkan bahawa (1) kitar semula dengan jelas menyumbang kepada pengurangan

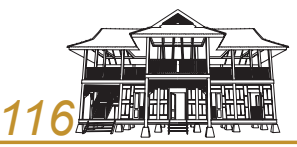


tenaga dan mengawal pelepasan $\mathrm{CO} 2$, di mana kitar semula mekanikal menghasilkan faedah alam sekitar lebih tinggi daripada teknologi kitar semula bahan mentah untuk plastik sisa pepejal. (2) Bahan kitar semula adalah lebih kepada insinerator/tapak pelupusan sisa purata di Jerman pada pertengahan 1990-an. Kajian yang dilakukan oleh Wollny et al. (2001) telah menunjukkan kesan alam sekitar iaitu melibatkan perubahan iklim terhadap penggunaan plastik. Pendekatan kajian beliau melibatkan agen dalam relau bagas, proses pirolisis BASF dan proses penegasan SVZ beberapa kitar semula kimia dan membuat perbandingan terhadap pemulihan tenaga.

Sejak kebelakangan ini, pelbagai kajian telah dilakukan oleh penyelidik terdahulu dalam memberi tumpuan kepada jenis sisa plastik tertentu dan faedah kitar semula. Sebagai contoh, pada kitaran hayat polietilena (PE)/polistirena berkembang (EPS) kitar semula pembungkusan di Australia telah dijalankan oleh Ross dan Evans (2003) dan hasilnya menunjukkan bahawa kitar semula sebahagian besarnya boleh mengurangkan beban alam sekitar pembungkusan plastik dan penggunaan tenaga oleh pengangkutan boleh dikurangkan berbanding dengan penggunaan tenaga keseluruhan sistem. Lindahl dan Winsnes (2005) yang dilakukan pengiraan mengenai kitar semula plastik kabel (terutamanya PE dan PVC) di mana proses Vinyloop proses dan proses Stigsnaes telah digunakan sebagai kitar semula mekanikal dan kitar semula kimia masing-masing yang berpangkalan di Sweden. Perbandingan menunjukkan proses Vinyloop adalah lebih baik untuk proses Stigsnaes, tetapi kemudian mempunyai keutamaan di lokasi di Denmark daripada pertumbuhan Vinyloop di Itali. Di Perugini, Mastellone dan Arena (2005) mengkaji bahan untuk dikitar semula secara mekanikal dan bahan mentah PE dan PP di Itali, kitar semula bahan mentah yang memberi tumpuan kepada proses pirolisis BP dan proses pemecahan hidro VEBA OEL. Hasilnya menunjukkan bahawa pilihan kitar semula secara mekanikal merupakan satu cara yang paling mesra alam dan kitar semula bahan makanan mempunyai beberapa indeks mesra alam yang berharga. Dodbiba et al. (2007) membuat kajian berkenaan pemulihan tenaga daripada bahan kitar semula sisa plastik dari set televisyen dibuang (terutamanya PE, PVC, PS) hasilnya menunjukan bahawa kitar semula secara mekanikal lebih berkesan. Lazarevic et al. (2010) telah mengkaji kitaran hayat sisa plastik dan diselesaikan dengan kunci parameter dan andaian boleh dibuat di akhir kajian.

\subsection{Plastik PVC Flex}

Plastik PVC Flex adalah jenama terkenal kain tampal, PVC flex dibuat daripada PVC berkualiti tinggi dan bahan mentah kain, direka khas untuk industri percetakan pelarut. la sesuai untuk percetakan dalaman dan luaran digunakan dalam papan iklan, paparan, banner dan pameran gerai hiasan. PVC Flex mempunyai sifat-sifat kimia yang stabil dan dakwat penyerapan yang sangat baik dan sering digunakan untuk percetakan imej digital untuk pengiklanan. Bagi memenuhi kualiti yang tinggi dan perkhidmatan

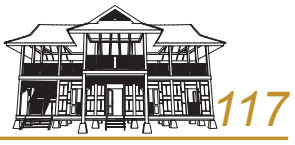


jualan terbaik pada masa kini, PVC Flex memainkan peranan yang penting dalam penghasilan papan tanda.

PVC Flex Banner merupakan satu bahan yang fleksibel dan tahan lama serta tahan daripada kekotoran. lanya diperbuat daripada lapisan PVC kain plastik dan boleh dibuat daripada pelbagai rangka kerja sama ada sebelum atau selepas dihiasi. lanya juga mempunyai polister didalamnya dan mempunyai permukaan yang halus separa licin. Bahan ini boleh dijadikan dua permukaan hadakan dan belakang kerana sifat fizikalnya yang sedikit berbeza.

Terdapat pelbagai jenis kategori sisa yang berlainan yang boleh melibatkan dengan sisa plastik (Christensen 2010) tetapi biasanya ianya tidak stabil dan sukar untuk dikesan dan tidak diambilkira di dalam laporan ini antaranya adalah seperti berikut:

- Sisa Perdagangan

- Sisa pembinaan dan perobohan

- Bahan buangan pertanian

- Sisa dari peperangan

- Sisa daripada bencana alam 


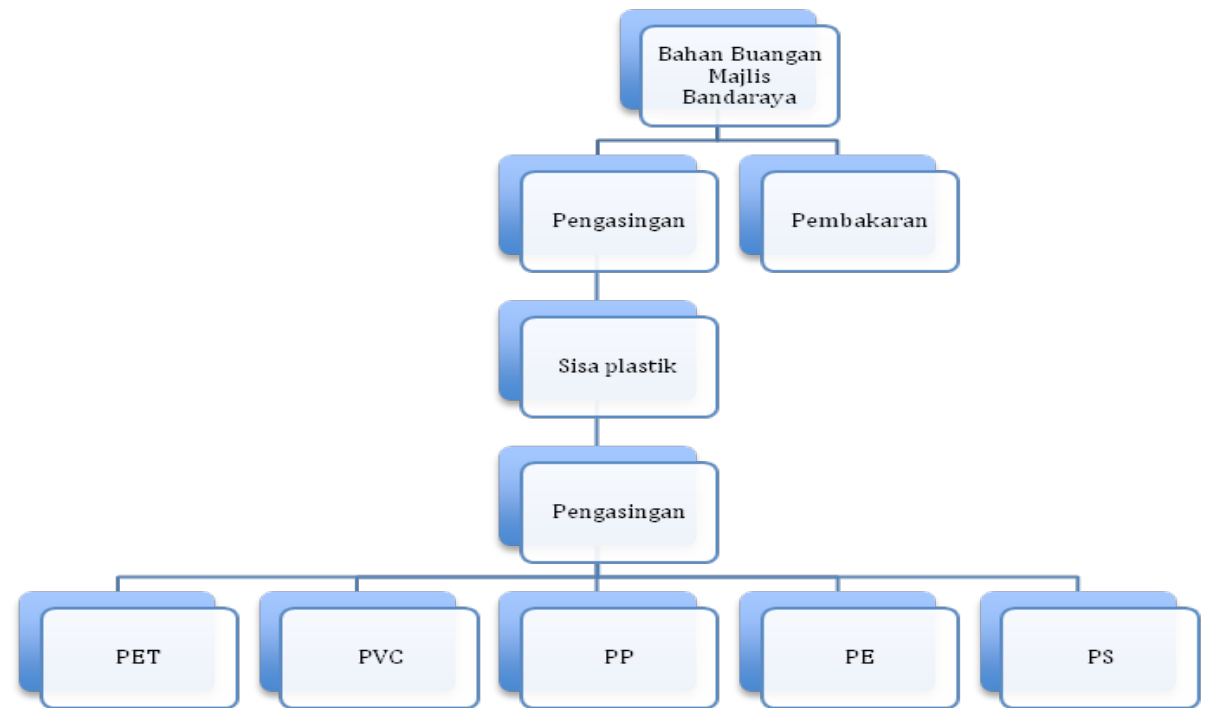

Rajah 2: Proses pengasingan jenis plastik

Proses penghasilan produk bahan buangan plastik banner dapat dikukuhkan lagi hasil kajian yang dijalankan, yang mana jenis plastik diasingkan terlebih dahulu mengikut warna, jenis serta saiz. Plastik banner diperolehi daripada industri pengiklanan yang terpilih, iaitu industri kitar semula dan Majlis perbandaraan Kemaman. Segala kerja-kerja teknikal dalam penghasilan dijalankan di Kolej Universiti TATI, kemaman Terengganu.
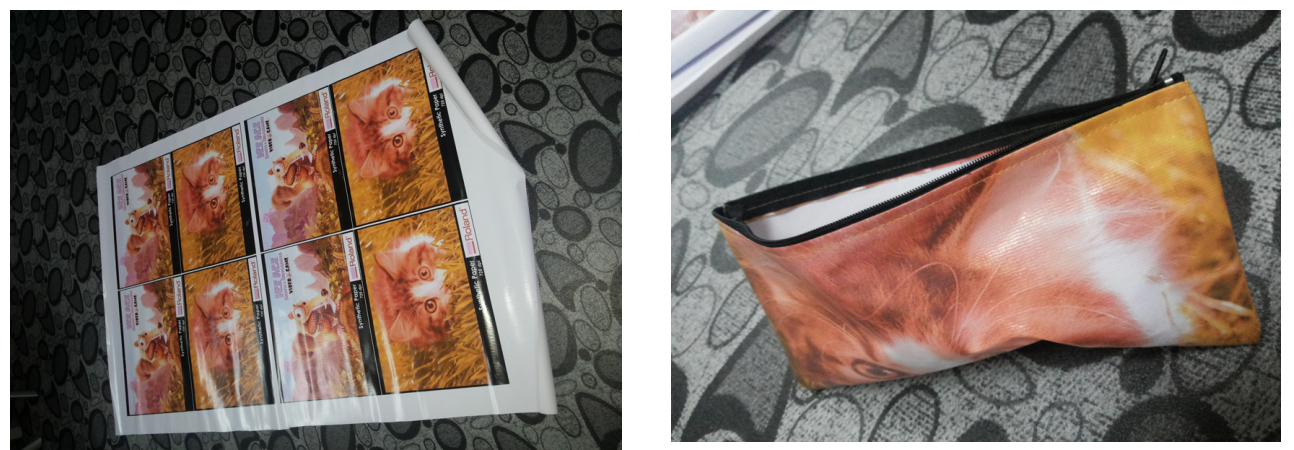

Rajah 3: Hasil penghasilan produk daripada bahan buangan plastik Banner

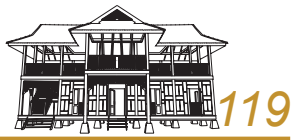




\subsection{Kesimpulan}

Memandangkan nilai pasaran bahan-bahan mentah untuk menghasilkan plastik semakin meningkat, jelas menunjukan bahawa nilai plastik banner secara tidak langsung juga meningkat sebenarnya. Sekiranya plastik banner terpakai ini tidak dimanipulasi kepada sesuatu yang memberi manfaat sudah tentulah ia bukan sahaja dilihat sebagai penyumbang kepada pencemaran alam sekitar, berdasarkan amalan pembakaran yang diamalkan oleh kebanyakan pengusaha pengiklanan dan badan berkanun kerajaan merupakan satu pembaziran.

Berdasarkan keputusan hasil kajian yang dilakukan, ia menunjukan bahawa objektif kajian ini mencapai keputusan yang positif. Bahan buangan plastik banner dilihat berupaya untuk diimplementasikan sebagai produk baru, produk kreatif ini jika diusahakan secara berterusan akan dapat meningkatkan serta mempelbagaikan produk bagi industri kraf negara.

Pada masa yang sama, kajian ini juga membantu dalam usaha perkembangan R\&D (Research and Development) serta juga membantu dalam usaha perkembangan produk baru yang turut memperkenalkan idea yang inovatif bagi menghasilkan produk. Penghasilan produk produk kreatif ini sudah tentulah akan memberi sesuatu yang baru kepada industri hiasan dalaman dan sebagainya berdasarkan keunikan hasil ini.

\section{Rujukan}

Aguado J., Serrano D. P. and San Miguel G. 2006. "European trends in the feed stock recycling of plastic wastes." Global NEST, 12-19.

AISalem, S. M., Lettieri P. and Baeyens J. 2009. "Recycling and recovery route so plastic solid waste (PSW): Are view."Waste Management pp 2625-2643.

Preben A. 2011. Aalborg Portland -Environmental Report 2010. Aalborg Portland A/S.

Bez J., and Nürrenbach T. 2001. Feed stock recycling of plastic waste in the polymer cracking process of the BP-Consortium. Fraunhofer-Institut Final Report for Association of Plastics

Manufacturers in Europe (APME) 2001. Darmstadt, Germany:Fraunhofer-Instit.

Biddle, M. 1999. An Overview of Recycling Plastics from Durable Goods: Challenges and Opportunities. Belgium: Indentiplast II.

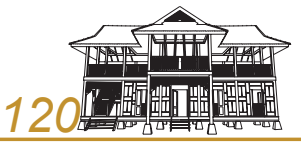


Broek, V. 1997. Chemometrics in spectroscopic near infrared imaging for plastic material recognition. Doctorate thesis, Netherland: Katholieke Universiteit Nijmegen.

Buch-Andersen, T. 2005. Recycling around the world.

Buley, J. 2011. "Plastic Surgery for Copenhagen's Recycling Policy. "Global Alliance for Incinerator Alternatives.

Christensen, T.H. 2010. (eds.). Solid Waste Technology \& Management .Chichester: John Wiley \& Sons, Ltd.

Grafisk J. 2009. City of Copenhagen-The Technical and Environmental Administration. Carbonneutralby 2025-Climate Plan Copenhagen. Copenhagen:

Clean Up Australia 2010. Report on action stored ucecirculation of single use plastic bags around the world. Clean Up Australia.

Cole, M., P. Lindeque P., Halsband, C. and Galloway T. S. 2011. "Micro plastics as contaminants in the marine environment: Are view." Marine Pollution Bulletin, 2588-2597.

Consult with Søren Løkke and Jannick Schmidt (29May2012)

Consult with Søren Løkke during supervision (May2012)

Copenhagen Municipality. Families in Copenhagen by type of family. 01Jan.2011. 


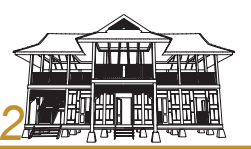

TENIAT 